\title{
The fisheries resources at sub-zones irrigation works of Omon - Xano and Quan Lo - Phung Hiep in the Ca Mau peninsula
}

\author{
Van V. Mai \\ College of Aquaculture and Fisheries, Can Tho University, Can Tho, Vietnam
}

\begin{abstract}
ARTICLE INFO
Research Paper

Received: July 23, 2018

Revised: September 29, 2018

Accepted: October 17, 2018
\end{abstract}

\section{Keywords}

Ca Mau Peninsula

Fish

Fishery resources

Management

Shrimp

Corresponding author

Mai Viet Van

Email: mvvan@ctu.edu.vn

\begin{abstract}
A study on the fisheries resources at sub-zones irrigation works of O MonXa No and Quan Lo-Phung Hiep in the Ca Mau Peninsula was conducted from January to December 2016. The data on fish species compositions were collected from the field in six times a year in combination with using the prepared questionaire for interviews of 240 fishing households inside and outside the irrigation system (IS) area in two freshwater and brackish water ecosystems. The results showed that the composition of fish species in the study area was diverse. The size of major fish species recorded in the study area was relatively small. The production of fish and shrimp in 2016 decreased by $50-60 \%$ as compared to 2012 and the production inside the IS area was lower than that outside the IS area in both ecosystems. Some indigenous fish species, such as Channalucius, Notopterus notopterus, Clarias macrocephalus, Clarias batrachus, Morulius chrysophekadion and Toxotes chatareus were rarely found in freshwater ecosystems. Similarly, the indigenous fish species of Arius maculatus and Otolithoides biauritus were rarely found in brackish water. Pterygoplichthys disjunctivus has established populations in many natural water bodies in this study area resulting in a threat to competition, diversity and abundance of indigenous fish species. There were many reasons for the significant decline of fisheries resources; for example, the IS has blocked the migration of aquatic species. Many fishermen used electricity, poisoning, catching broodfish and fry during breeding season and water pollution by waste from aquaculture pond rehabilitation in the study area. Thus, it is necessary to deploy a community-based model of fishery resources management and preservation in the Ca Mau Peninsula.
\end{abstract}

Cited as: Mai, V. V. (2019). The fisheries resources at sub-zones irrigation works of Omon - Xano and Quan Lo - Phung Hiep in the Ca Mau peninsula. The Journal of Agriculture and Development 18(1), 98-108. 


\title{
Nguồn lợi thủy sản tại tiểu vùng dự án thủy lợi Ô Môn - Xà No và Quản Lộ - Phụng Hiệp ở bán đảo Cà Mau
}

\author{
Mai Viết Văn \\ Khoa Thủy Sản, Trường Đại Học Cần Thơ, Cần Thơ
}

\section{THÔNG TIN BÀI BÁO}

Bài báo khoa học

Ngày nhận: 23/07/2018

Ngày chỉnh sửa: 29/09/2018

Ngày chấp nhận: 17/10/2018

\section{TÓM TẮT}

Nguồn lợi thủy sản tại tiểu vùng dự án thủy lợi Ô Môn - Xà No và Quản Lộ - Phụng Hiệp ở Bán đảo Cà Mau đã được thực hiện từ tháng 1 dến tháng 12 năm 2016. Số liệu nguồn lợi thủy sản được thu thập qua 6 đợt tại hiện trường kết hợp với phỏng vấn 240 hộ ngư dân bằng bảng câu hỏi soạn sẵn ở bên trong và bên ngoài hệ thống công trình thủy lợi (HTCTTL) ở hệ sinh thái (HST) nước ngọt và HST nước lợ. Kết quả cho thấy thành phần loài cá, tôm ở vùng nghiên cứu rất đa dạng. Sản lượng cá, tôm khai thác năm 2016 đã bị suy giảm 50 - 60\% so với năm 2012 và sản lượng bên trong HTCTTL thấp hơn bên ngoài HTCTTL ở cả hai HST. Kích cỡ các loài cá, tôm khai thác tương đối nhỏ. Một số loài cá bản địa rất ít khi xuất hiện ở HST nước ngọt như Channa lucius, Notopterus notopterus, Clarias macrocephalus, Clarias batrachus, Morulius chrysophekadion và Toxotes chatareus, tương tự ở HST nước lợ có Arius maculatus và Otolithoides biauritus. Loài Pterygoplichthys disjunctivus dã thiết lập quần đàn trên nhiều thủy vực gây cạnh tranh, đe dọa tính đa dạng và sự phong phú của các loài cá bản địa. Có nhiều nguyên nhân gây nên sự suy giảm đáng kể nguồn lợi thủy sản (NLTS) ở vùng nghiên cứu như HTCTTL ngăn chặn đường di cư của các loài thủy sản, nhiều ngư dân sử dụng xiệc điện, thuốc độc, bắt cá bố mẹ và cá con trong mùa sinh sản và môi trường nước ô nhiễm bởi các chất thải từ hoạt động cải tạo ao/đầm nuôi trồng thủy sản ở vùng nghiên cứu. Vì thế, cần xây dựng mô hình quản lý và bảo tồn nguồn lợi thủy sản dựa vào cộng đồng ở Bán đảo Cà Mau.

Mai Viết Văn

Email: mvvan@ctu.edu.vn

\section{1. Đặt Vấn Đề}

Bán đảo Cà Mau (BĐCM) nằm ở phía Tây Nam Đồng bằng sông Cửu Long (ĐBSCL), giới hạn bởi phía Bắc là kênh Cái Sắn, phía Đông Bắc là sông Hậu, phía Tây Nam là biển Tây và phía Đông là biển Đông. Diện tích tự nhiên 16.780 $\mathrm{km}^{2}$, chiếm $43 \%$ diện tích ĐBSCL được phân thành 7 tiểu vùng sinh thái và 51 khu thủy lợi gồm 6 tỉnh: Bạc Liêu, Sóc Trăng, Cà Mau, Hậu Giang, Thành phố Cần Thơ và một phần của tỉnh Kiên Giang (Mai \& ctv., 2016). Hệ thống côn trình thủy lợi (HTCTTL) khu vực BĐCM được đầu tư quy hoạch xây dựng khá tốt với nhiều mục tiêu khác nhau, trong đó mục tiêu phục vụ cho sản xuất nông nghiệm chiếm vai trò rất lớ. Mặc dù đây là vùng trọng điểm nuôi trồng thủy sản của ĐBSCL nhưng đến nay vẫn chưa có một
HTCTTL riêng phục vụ cho mục đích này (Dang, 2010). Các vấn đề nảy sinh, cho đến nay vẫn còn chưa giải quyết được, nhất là việc cấp nước chủ động cho các tiểu vùng theo nhu cầu của từng đối tượng sản xuất (Tang, 2011). Tác động lớn nhất của các dự án thủy lợi đến thủy sản chính là việc xây dựng công trình đê bao và hệ thống cống của các tiểu dự án đã làm giảm diện tích khai thác cá, ảnh hưởng đến sự di cư của các loài cá tự nhiên và giảm khả năng khai thác cá trong vùng kiểm soát lũ. Kết quả báo cáo giữa kỳ Dự án phát triển thủy lợi ĐBSCL, Haskoning \& ctv. (1997) đã ước tính lượng tổn thất cá trong vùng tiểu dự án thủy lợi Ô Môn- Xà No là 1.612 tấn/năm và nghiên cứu của Trường Đại học Cần Thơ ước tính sản lượng tổn thất cá của vùng này khoảng 400 tấn/năm. Sản lượng khai thác thủy sản bình quân/hộ của vùng $\mathrm{BĐCM}$ có sự giảm đáng kể từ 
1.091,1 kg cá/hộ/năm (2000) xuống còn 653,7 kg cá/hộ/năm (2006) tương ứng với mức giảm bình quân là 9-10\%/năm. Một số loài thủy sản có giá trị kinh tế cao cũng bị giảm về số lượng cũng như sản lượng và cũng có nguy cơ bị mất đi như: cá ét mọi, cá dày, cá bông lau, cá trê vàng (Le \& ctv., 2007). Đã và đang có rất nhiều tranh luận quanh những tác động về mặt môi trường và kinh tế-xã hội của các công trình thủy lợi ở $\mathrm{BĐCM}$, trong đó tác động đối với NLTS cũng như các hoạt động thủy sản của cộng đồng chưa được quan tâm một cách đúng mức. Vì vậy, đề tài nghiên cứu "Nguồn lợi thủy sản tại tiểu vùng dự án thủy lợi Ô Môn - Xà No và Quản Lộ - Phụng Hiệp ở Bán đảo Cà Mau" đã được thực hiện nhằm cung cấp các thông tin về hiện trạng nguồn lợi thủy sản ở bên trong và bên ngoài HTCTTL ở HST nước ngọt và HST nước lợ, làm cơ sở khoa học cho việc đề xuất các giải pháp quản lý và bảo tồn nguồn lợi thủy sản ở vùng nghiên cứu.

\section{Vật Liêuu và Phương Pháp Nghiên Cứu}

\subsection{Thời gian và địa điểm nghiên cứu}

Thời gian triển khai nghiên cứu: từ tháng 01 đến tháng 12 năm 2016.

Giới hạn địa bàn nghiên cứu là $\mathrm{BĐCM}$ với 02 vùng sinh thái đại diện là hệ sinh thái nước ngọt (HST nước ngọt-chịu tác động của hệ thống thủy lợi Ô Môn - Xà No) và hệ sinh thái nước lợ (HST nước lợ-chịu tác động của hệ thống thủy lợi Quản Lộ - Phụng Hiệp).

\subsection{Phương pháp thu thập số liệu}

Số liệu thứ cấp được thu thập từ các sở ban ngành trong vùng nghiên cứu và từ các tài liệu đã được xuất bản trong và ngoài nước có liên quan đến hiện trạng khai thác cá tự nhiên ở vùng nghiên cứu.

Số liệu sơ cấp được thu thập trực tiếp nguồn lợi cá, tôm phân bố tại hiện trường và kết hợp với phỏng vấn hộ ngư dân khai thác cá ở vùng nghiên cứu.

\subsubsection{Thu thập mẫu cá, tôm tại hiện trường vùng nghiên cứu}

Mẫu cá, tôm được thu thập trong suốt năm với nhịp thu mẫu định kỳ hai tháng/đợt. Phạm vi khảo sát tại các thủy vực của HST nước ngọt và HST nước lợ như sau:
Sông cấp 1: Thu mẫu cá, tôm ở sông Ô Môn (đoạn từ vàm Ô Môn đến thị trấn Thới Lai, T.p Cần Thơ). Ngư cụ khai thác bằng lưới kéo lưới rê, chài và đăng mé.

Sông cấp 2: Thu mẫu cá, tôm ở sông Kênh Đứng (xã Đông Thắng, huyện Cờ Đỏ, Thành phố Cần Thơ), sông Gành Hào-Hộ Phòng (huyện Giá Rai và Đông Hải, tỉnh Bạc Liêu), sông Cái Lớn (Đoạn từ ngã ba Đình đến chợ Cầu Đỏ (giáp huyện Vĩnh Thuận-Kiên Giang và huyện Hồng Dân-Bạc Liêu) và sông Bạc Liêu-Cà Mau. Trên mỗi sông thu mẫu 3 điểm (đầu, giữa và cuối) bằng các loại ngư cụ khác nhau như lưới kéo, lưới rê, chài, đăng mé và đáy.

Kênh/Rạch: Thu mẫu cá, tôm ở rạch Tra (Thới Lai), kênh Xà No (đoạn từ ngã ba vàm Xáng (Cần Thơ) đến thị trấn Một Ngàn (Hậu Giang), Một số kênh nhánh xương cá dọc theo kênh Xà No (thuộc Phong Điền Cần Thơ và huyện Châu Thành-Hậu Giang); kênh Cạnh Đền-Hộ Phòng (Giá Rai), kênh Quản Lộ-Phụng Hiệp (đoạn từ ấp Ninh Thành đến Ninh Qưới A-Hồng Dân), kênh Ngan Dừa (Hồng Dân), kênh Tám Ngàn (Hồng Dân). Mỗi kênh/rạch thu 3 mẫu (điểm đầu, giữa và cuối) bằng lưới kéo, lưới rê, đáy, chài, lợp, câu, lưới kéo tay.

Đồng/Ruộng: Thu mẫu cá, tôm ở 2 cánh đồng xã Đông Thắng (Thành phố Cần Thơ), 1 cánh đồng xã Ninh Thành (Hồng Dân), mỗi cánh đồng thu 1 mẫu bằng lưới rê, lú và lưới kéo tay.

Mẫu cá, tôm được bảo quản lạnh đến khi định danh theo quy trình phân tích mẫu nguồn lợi thủy sản của Khoa Thủy sản, Trường Đại học Cần Thơ. Mẫu sau khi phân tích được cố định trong formol $4 \%$, sau đó chuyển sang bảo quản trong Etanol $75 \%$ tại phòng thí nghiệm Bộ môn Quản lý và Kinh tế Nghề cá, Khoa Thủy sản, Trường Đại học Cần Thơ.

Hệ thống phân loại được sử dụng từ cấp lớp, bộ, họ, giống và loài dựa theo hệ thống phân loại của Eschmeyer (1998); ngoài ra còn tham khảo các tác giả như Mai \& ctv. (1992); Dang \& Ho (2001); Tran \& ctv. (2013). Đối chiếu các tên đồng vật (Synonyms) và cập nhật các tên được định danh dựa theo Froese \& Pauly (2018), Palomares \& Pauly (2018). 2.2.2. Thu thập thông tin phỏng vấn bằng bảng
câu hỏi soạn săn

Đối tượng phỏng vấn là những hộ có tham gia khai thác nguồn lợi thủy sản tự nhiên đang sinh 
sống trong vùng nghiên cứu. Tổng số mẫu điều tra là 240 hộ, trong đó có 120 hộ trong HTCTTL vùng nghiên cứu (Trong) và 120 hộ nằm ngoài HTCTTL vùng nghiên cứu (Ngoài) (Bảng 1).

\subsection{Phương pháp xử lý và phân tích số liệu}

Phần mềm SPSS for Windows (13.0) được dùng để xử lý và phân tích số liệu thu thập được. Phương pháp thống kê mô tả, thống kê nhiều chọn lựa, các giá trị trung bình, độ lệch chuẩn, tần số $(\%)$ được sử dụng để mô tả các hoạt động khai thác thủy sản ở vùng nghiên cứu.

\section{Kết Quả và Thảo Luận}

\subsection{Thành phần loài cá, tôm phân bố ở vùng nghiên cứu}

Kết quả khảo sát nguồn lợi cá phân bố bên trong và ngoài HTCTTL ở hai hệ sinh thái năm 2016 đã ghi nhận được 91 loài cá thuộc 67 giống, 33 họ, 11 bộ phân bố ở HST nước ngọt (Bảng 2 và Bảng 3 ) và 107 loài cá thuộc 89 giống, 56 họ, 15 bộ phân bố ở HST nước lợ (Bảng 2 và Bảng $4)$.

Bộ Perciformes và Siluriformes là 2 bộ có số lượng loài cá phân bố nhiều nhất ở cả hai hệ sinh thái. Trong cả hai bộ này có rất nhiều loài cá có giá trị thương phẩm và có sản lượng khai thác tương đối ổn định, đóng góp vai trò quan trọng trong sinh kế cộng đồng.

Về nguồn lợi tôm, đã thu thập được 7 loài tôm thuộc 3 giống, 2 họ, 1 bộ phân bố ở HST nước ngọt và 16 loài tôm thuộc 8 giống, 4 họ, 2 bộ phân bố ở HST nước lợ (Bảng 5).

Đa số các giống loài tôm phân bố ở HST nước ngọt dều thuộc họ tôm càng (Caridea), như tôm càng xanh (Macrobrachium rosenbergii), tép thợ rèn (Macrobrachium sintangense), tôm trứng (Macrobrachium equidens), tép trấu (Macrobrachium idea), tép bầu (Macrobrachium mamillodactylus), tép mồng sen (Macrobarachi mirabile), tép rong (Macrobrachium lanchesteri), kích cỡ khai thác các loài tôm này tương đối nhỏ, sản lượng ít, có giá trị thương phẩm không cao (trừ tôm càng xanh) nhưng là nguồn thực phẩm quan trọng đối với cộng đồng ở địa phương.

Ở HST nước lợ thì đa số các loài thuộc họ tôm he (Penaeidae) có 15 loài (chiếm 93,7\% so với tổng các loài trong bộ mười chân), đại diện có các loài tôm sú (Penaeus monodon), tôm đất (Metapenaeus ensis), tôm bạc nghệ (Metapenaeus brevicornis), tôm thẻ đuôi đỏ (Fenneropennaeus indicus), tôm sắc rằn (Parapenaeopsis cultrirostris)... hầu hết các loài tôm này dều là loài có giá trị thương phẩm cao, đặc biệt loài tôm sú và tôm thẻ còn là các đối tượng nuôi xuất khẩu.

Kết quả khảo sát thực địa cũng cho thấy thành phần loài cá phân bố nhiều nhất ở thủy vực sông và kênh ở cả HST nước ngọt và HST nước lợ. Các thủy vực khác có số lượng loài cá phân bố ít hơn đặc biệt là ở thủy vực ruộng lúa vì bị tác động của các hoạt động canh tác lúa 2 - 3 vụ/năm (Bảng $6)$.

Kết quả khảo sát cũng cho thấy có khoảng 18 và 19 loài thủy sản khai thác thường xuyên ở sông rạch và ruộng thuộc HST nước ngọt. Trong khi ở HST nước lợ thì có khoảng 16 loài thủy sản được khai thác ở sông rạch. Các đối tượng cho sản lượng khai thác cao trong mùa lũ gồm có cá sặc bướm, cá dãnh, cá mè vinh, cá linh rìa siêm, cá rô đồng, cá bống trứng và ốc bươu vàng ở trên ruộng và kênh rạch HST nước ngọt. Ở thủy vực sông rạch HST nước lợ thì một số loài cá rô phi đen, cá đối đất, cá chốt, cá kèo và tôm đất, tôm bạc chiếm tỷ lệ cao về sản lượng trong mẻ khai thác.

Một số loài cá ít được bắt gặp trong khi khai thác thủy sản tự nhiên ở HST nước ngọt gồm có cá dầy (Channa lucius), cá thác lác (Notopterus notopterus), cá trê vàng (Clarias macrocephalus), cá trê trắng (Clarias batrachus), cá ét mọi (Morulius chrysophekadion) và cá mang rỗ (Toxotes chatareus). Trong khi cá lau kính (Pterygoplichthys disjunctivus) thì xuất hiện ở hầu hết các loại hình thủy vực nước ngọt. Ở HST nước lợ hiện nay các loài cá úc thép (Arius maculatus) và cá sửu vàng (Otolithoides biauritus) rất ít được bắt gặp. Nhìn chung, những loài thủy sản có giá trị thương phẩm cao, những loài có sức sống và sức sinh sản thấp hoặc những loài được tận thu để làm thức ăn cho nghề nuôi trồng thủy sản là những loài có nguy cơ suy giảm cao nhất.

Theo kết quả nghiên cứu Le \& ctv. (2007) có 31 loài thủy sản tự nhiên có giá trị kinh tế đã được người dân ở địa bàn nghiên cứu cho biết là đã khai thác được ở tiểu vùng thủy lợi Ô Môn-Xà No thuộc HST nước ngọt (tính cả ốc bươu vàng). Bảy loài thủy sản có tần suất khai thác được cao nhất ở địa bàn nghiên cứu là cá rô đồng, cá sặc bướm, cá lóc, cá trê, cá mè vinh, tép trấu, 
Bảng 1. Cơ cấu mẫu điều tra tại vùng nghiên cứu

\begin{tabular}{lcccccc}
\hline \multirow{2}{*}{ Huyện } & \multicolumn{2}{c}{ HST nước ngọt } & \multicolumn{2}{c}{ HST nước lợ } & \multicolumn{2}{c}{ Tổng số } \\
\cline { 2 - 7 } & Trong & Ngoài & Trong & Ngoài & Trong & Ngoài \\
\hline Xã Đông Thắng - Huyện Cờ Đỏ & 0 & 60 & 0 & 0 & 0 & 60 \\
Xã Trường Long - Huyện Phong Điền & 30 & 0 & 0 & 0 & 30 & 0 \\
Xã Thới Thạnh - Huyện Thới Lai & 30 & 0 & 0 & 0 & 30 & 0 \\
Xã An Trạch - Huyện Đông Hải & 0 & 0 & 0 & 60 & 0 & 60 \\
Xã Phong Thạnh Tây - Huyện Giá Rai & 0 & 0 & 30 & 0 & 30 & 0 \\
Xã Phong Thạnh A - Huyện Giá Rai & 0 & 0 & 30 & 0 & 30 & 0 \\
\hline Tồng số & 60 & 60 & 60 & 60 & 120 & 120 \\
\hline
\end{tabular}

Bảng 2. Cấu trúc thành phần loài cá phân bố bên trong và bên ngoài các hệ sinh thái

\begin{tabular}{cccccccc}
\hline \multirow{2}{*}{ TT } & \multirow{2}{*}{ Nội dung } & \multicolumn{3}{c}{ HST nước ngọt } & \multicolumn{3}{c}{ HST nước lợ } \\
\cline { 3 - 8 } & & Trong & Ngoài & Vùng ngọt & Trong & Ngoài & Vùng lợ \\
\hline 1 & Bộ & 8 & 11 & 11 & 14 & 14 & 15 \\
2 & Họ & 26 & 33 & 33 & 44 & 43 & 56 \\
3 & Giống & 41 & 62 & 67 & 64 & 43 & 89 \\
4 & Loài & 52 & 79 & 91 & 79 & 83 & 107 \\
\hline
\end{tabular}

Bảng 3. Cấu trúc thành phần loài cá phân theo Bộ ở hệ sinh thái nước ngọt

\begin{tabular}{cccccccc}
\hline \multirow{2}{*}{ TT } & \multirow{2}{*}{ Bộ } & \multicolumn{2}{c}{ Họ } & \multicolumn{2}{c}{ Giống } & \multicolumn{2}{c}{ Loài } \\
\cline { 3 - 8 } & Số lượng & $\%$ & Số lượng & $\%$ & Số lượng & $\%$ \\
\hline 1 & Osteoglossiformes & 1 & 3,03 & 2 & 2,99 & 2 & 2,2 \\
2 & Aguilliformes & 1 & 3,03 & 1 & 1,49 & 1 & 1,1 \\
3 & Clupeiformes & 2 & 6,06 & 2 & 2,99 & 2 & 2,2 \\
4 & Cypriniformes & 2 & 6,06 & 20 & 29,85 & 26 & 28,6 \\
5 & Charactiformes & 1 & 3,03 & 1 & 1,49 & 1 & 1,1 \\
6 & Siluriformes & 6 & 18,18 & 11 & 16,42 & 18 & 19,8 \\
7 & Benloniformes & 2 & 6,06 & 3 & 4,48 & 4 & 4,4 \\
8 & Synbranchiformes & 2 & 6,06 & 4 & 5,97 & 6 & 6,6 \\
9 & Perciformes & 13 & 39,39 & 20 & 29,85 & 26 & 28,6 \\
10 & Pleuronectiformes & 2 & 6,06 & 2 & 2,99 & 4 & 4,4 \\
11 & Tetraodontiformes & 1 & 3,03 & 1 & 1,49 & 1 & 1,1 \\
\hline & Tổng cộng & 33 & 100 & 67 & 100 & 91 & 100 \\
\hline
\end{tabular}

lươn. Trong đó, cá rô đồng và cá sặc bướm xuất hiện nhiều trên ruộng, cá mè vinh có nhiều trên sông, trong khi cá lóc phổ biến ở cả trên ruộng và trong ao/ mương. Lươn đồng là loài bắt được nhiều trong ao/mương. Hiện nay, số lượng các loài thủy sản thường xuyên bắt gặp trong khai thác ngày càng giảm (ít hơn 10 loài so với 2007) do nhiều nguyên nhân (mục 3.5).

\subsection{Ngư trường, ngư cụ và mùa khai thác}

Hầu hết các hộ khai thác thủy sản tự hiên ở vùng nghiên cứu đều tham gia hoạt động ở một, hai hoặc cả ba loại ngư trường: trên ruộng, trên sông, rạch hoặc trong ao/mương không nuôi thủy sản tại vùng nghiên cứu. Lưới cào, vó, lờ/lợp, chài và chỉa... là các ngư cụ chỉ được dùng khi khai thác trên sông rạch trong khi kéo côn và đẩy ốc/bắt ốc... hầu như chỉ được dùng trên ruộng. Mùa vụ khai thác được tính căn cứ vào thời điểm bắt đầu và kết thúc của mỗi mùa hoạt động của từng loại ngư cụ theo ngư trường. Do có nhiều loại ngư cụ được sử dụng trên mỗi ngư trường nên thời gian khai thác trên từng ngư trường được tính chung cho các loại ngư cụ, ngắn nhất là 1 tháng/năm và dài nhất là 12 tháng/năm (quanh năm). Các hoạt động khai thác trên đồng ruộng ở HST nước ngọt thường kéo dài 4 - 5 tháng, 
Bảng 4. Cấu trúc thành phần loài cá phân theo Bộ ở hệ sinh thái nước lợ

\begin{tabular}{cccccccc}
\hline \multirow{2}{*}{ TT } & \multirow{2}{*}{ Bộ } & \multicolumn{2}{c}{ Họ } & \multicolumn{2}{c}{ Giống } & \multicolumn{2}{c}{ Loài } \\
\cline { 3 - 8 } & & Số lượng & $\%$ & Số lượng & $\%$ & Số lượng & $\%$ \\
\hline 1 & Myliobatiformes & 1 & 1,79 & 1 & 1,12 & 1 & 0,93 \\
2 & Elopiformes & 2 & 3,57 & 2 & 2,25 & 2 & 1,87 \\
3 & Osteoglossiformes & 1 & 1,79 & 2 & 2,25 & 2 & 1,87 \\
4 & Anguiliformes & 4 & 7,14 & 4 & 4,49 & 5 & 4,67 \\
5 & Clupeiformes & 2 & 3,57 & 5 & 5,62 & 5 & 4,67 \\
6 & Cypriniformes & 2 & 3,57 & 4 & 4,49 & 4 & 3,74 \\
7 & Siluriformes & 6 & 10,71 & 6 & 6,74 & 9 & 8,41 \\
8 & Batrachoiformes & 2 & 3,57 & 2 & 2,25 & 2 & 1,87 \\
9 & Cyprinodontiformes & 2 & 3,57 & 2 & 2,25 & 2 & 1,87 \\
10 & Beloniformes & 2 & 3,57 & 3 & 3,37 & 3 & 2,80 \\
11 & Synbranchiformes & 2 & 3,57 & 2 & 2,25 & 2 & 1,87 \\
12 & Scorpaeniformes & 1 & 1,79 & 1 & 1,12 & 1 & 0,93 \\
13 & Perciformes & 26 & 46,43 & 50 & 56,18 & 61 & 57,01 \\
14 & Pleuronectiformes & 2 & 3,57 & 2 & 2,25 & 5 & 4,67 \\
15 & Tetraodontiformes & 1 & 1,79 & 3 & 3,37 & 3 & 2,80 \\
\hline & Tổng cộng & 56 & 100 & 89 & 100 & 107 & 100 \\
\hline
\end{tabular}

Bảng 5. Cấu trúc thành phần loài tôm phân bố ở 2 hệ sinh thái nước ngọt và hệ sinh thái nước lợ

\begin{tabular}{ccccccccc}
\hline \multirow{2}{*}{ TT } & \multirow{2}{*}{ Bộ } & \multicolumn{2}{c}{ Họ } & \multicolumn{3}{c}{ Giống } & \multicolumn{2}{c}{ Loài } \\
\cline { 3 - 8 } & Số lượng & $\%$ & Số lượng & $\%$ & Số lượng & $\%$ \\
\hline HST nước ngọt & & & & & & \\
1 & DECAPODA & 2 & 100,0 & 2 & 100,0 & 7 & 100,0 \\
& Tổng cộng & 2 & 100,0 & 2 & 100,0 & 7 & 100,0 \\
\multirow{2}{*}{ HST nước lợ } & & & & & & \\
1 & DECAPODA & 3 & 75,0 & 7 & 87,5 & 15 & 93,7 \\
2 & STOMATOPODA & 1 & 25,0 & 1 & 12,5 & 1 & 6,3 \\
& Tổng cộng & 4 & 100 & 8 & 100 & 16 & 100 \\
\hline
\end{tabular}

Bảng 6. Biến động thành phần loài cá phân bố theo các loại hình thủy vực

\begin{tabular}{clc}
\hline & Thủy vực & Số lượng (loài) \\
\hline HST nước ngọt & Kênh & 91 \\
Trong & Sông & 52 \\
& Ruộng & 76 \\
Ngoài & Kênh & 11 \\
& & 13 \\
HST nước lợ & Kênh & 107 \\
& Ruộng & 73 \\
Trong & Ao/mương & 16 \\
& Đầm quãng canh & 6 \\
\multirow{2}{*}{ Ngoài } & Sông cấp 2 & 16 \\
& Sông cấp 1 & 51 \\
\hline
\end{tabular}

bắt đầu từ tháng 8 (khi nước lũ lên đồng) và kết Đối với HST nước lợ thì không có các hoạt động thúc trong tháng 12 (khi các hoạt động làm đất khai thác thủy sản trên ruộng. Hầu hết các hoạt cho gieo sạ lúa Đông Xuân được hoàn thành). động khai thác trên sông rạch ở HST nước ngọt 
có thể được thực hiện trong khoảng 6 tháng, tập trung từ tháng 11 (lúc nước lũ bắt đầu rút) cho tới tháng 3 (khi nước kiệt). Trong khi ở HST nước lợ thì các hoạt động khai thác kéo dài từ 7 đến 10 tháng/năm. Khai thác thủy sản trong ao mương không nuôi thủy sản được tập trung chủ yếu trong 3 tháng, từ tháng 12 tới hết tháng 3. Khai thác thủy sản ở thủy vực này ngày càng giảm cả về quy mô và số lượng do giảm sút về nguồn lợi thủy sản tự nhiên. Kết quả phân tích tần số xuất hiện các loại ngư cụ được sử dụng để khai thác thủy sản bên trong và bên ngoài các HST được trình bày qua Bảng 7 .

\subsection{Biến động sản lượng cá, tôm tự nhiên ở vùng nghiên cứu}

Kết quả điều tra phỏng vấn ngư dân ở vùng nghiên cứu cho thấy sản lượng cá, tôm khai thác tự nhiên năm 2016 giảm so với 2012 khoảng 50 - 60\%. Ở HST nước ngọt, sản lượng khai thác cá, tôm cao hơn HST nước lợ. Sản lượng cá, tôm khai thác bên ngoài HTCTTL cao hơn bên trong HTCTTL ở cả hai hệ sinh thái. Ở HST nước ngọt, sản lượng cá, tôm khai thác đạt $16,14 \mathrm{~kg} /$ tháng/hộ (Trong) và 57,76 kg/tháng/hộ (Ngoài). Thời gian khai thác cho sản lượng cao từ tháng 07 đến tháng 10. Thời gian này trùng với thời gian ngập lũ ở vùng hạ lưu sông MeKong, nên các vùng nước ngọt có độ ngập lũ trung bình như Cần Thơ, Vĩnh long, Hậu Giang. . . được bổ sung nguồn lợi thủy sản tự nhiên từ thượng nguồn đổ về. Đối với HST nước lợ, quanh năm ít chịu tác động của lũ sông MeKong, chủ yếu chịu ảnh hưởng của thủy triều nên sản lượng cá, tôm khai thác tương đối ổn định ở mức thấp hơn HST nước ngọt-chỉ đạt 10,89 kg/tháng/hộ (Trong) và 23,40 kg/tháng/hộ (Ngoài).

Kết quả điều tra phỏng vấn cho thấy sản lượng cá khai thác tự nhiên (2016) ở 2 hệ sinh thái biến động theo ngư cụ rất lớn. Ở HST nước ngọt, sản lượng cao tập trung ở ngư cụ lú dây (526,8 $\mathrm{kg} / \mathrm{năm}$ ở sông rạch) và dớn $(550,5 \mathrm{~kg} / \mathrm{năm}$ ở sông rach). Trong khi ở ruộng thì ngư cư lưới giăng và lú miệng lại cho sản lượng cao nhất (tương ứng $355 \mathrm{~kg} /$ năm và $456,5 \mathrm{~kg} / \mathrm{năm})$. Đối với HST nước lợ, chỉ có khai thác trên sông rạch là chính. Sản lượng cao nhất ở lưới giăng $(273,2 \mathrm{~kg} / \mathrm{năm})$, đáy (201 kg/năm) và lú miệng $(178,5 \mathrm{~kg} / \mathrm{năm})$ (Bảng $8)$.

Khi phân tích biến động sản lượng thủy sản ở vùng nghiên cứu cho thấy sản lượng khai thác thủy sản bình quân/hộ/năm bên trong HTCTTL ở HST nước ngọt giảm đáng kể từ $1.091,1 \mathrm{~kg}$ cá/hộ/năm (2000) giảm còn $278,7 \mathrm{~kg}$ cá/hộ/năm (2016). Tương tự, đối với bên ngoài HTCTTL thì sản lượng cá cũng suy giảm từ 1.505,3 kg cá/hộ/năm (2000) xuống còn 763,5 kg cá/hộ/năm (2016) (Bảng 9). Đối với HST nước lợ, do chưa tìm được các số liệu nghiên cứu trước đây để so sánh với kết quả nghiên cứu này, vì vậy chưa thể đưa ra các nhận định để đánh giá biến động sản lượng thủy sản khai thác ở HST này.

\subsection{Biến động kích cỡ một số loài cá khai thác thường xuyên}

Đa số các loài cá khai thác thường xuyên tại vùng nghiên cứu đều có kích cỡ tương đối nhỏ, một số loại có chiều dài tổng khoảng $1,8-5 \mathrm{~cm}$ đã bị khai thác (Bảng 10). Điều đó cho thấy kích thước mắc lưới các ngư cụ sử dụng khai thác cũng rất nhỏ $(2 \mathrm{a} \leq 10 \mathrm{~mm})$.

\subsection{Nguyên nhân suy giảm nguồn lợi thủy sản}

Qua khảo sát cho thấy có nhiều nguyên nhân đã làm cho sản lượng thủy sản tự nhiên suy giảm rất nhiều so với trước đây. Ở HST nước ngọt, có $55,8 \%$ số hộ cho rằng nguồn lợi thủy sản suy giảm là do HTCTTL đã ngăn chặn đường di cư của cá, tôm. Có 36,9\% số hộ đồng ý với quan điểm nước lũ về ít nên sản lượng cá bị suy giảm, kế đến là do sử dụng ngư cụ khai thác hủy diệt (35,1\%). 33,3\% hộ cho rằng khai thác cá mồi để phục vụ cho nuôi trồng thủy sản (nuôi cá lóc), và do canh tác lúa 3 vụ nên không có nơi cho cá cư trú và sinh sản để tái bổ sung quần đàn tự nhiên $(30,6 \%)$. Đối với HST nước lợ, $64 \%$ số hộ cho rằng suy giảm nguồn lợi thủy sản là do sử dụng ngư cụ khai thác hủy diệt, kế đến là khai thác cá con, cá bố mẹ mùa sinh sản (50\%), số người khai thác thủy sản tăng (42\%) và khoảng $13-25 \%$ số hộ cho rằng cống thủy lợi đã ngăn cản đường di cư của cá, tôm và làm cho ô nhiễm môi trường nước ảnh hưởng đến sự sống cả các loài thủy sản (Bảng 11).

\section{Kết Luận}

\subsection{Kết luận}

Nguồn lợi thủy sản tại một số tiểu vùng dự án thủy lợi ở Bán đảo Cà Mau đa dạng về thành phần loài. Sản lượng cá, tôm khai thác năm 2016 đã bị suy giảm 50 - 60\% so với năm 
Bảng 7. Các loại ngư cụ khai thác nguồn lợi thủy sản tự nhiên ở vùng nghiên cứu

\begin{tabular}{|c|c|c|c|c|c|c|c|}
\hline \multirow{2}{*}{$\mathrm{TT}$} & \multirow{2}{*}{ Ngu cự } & \multicolumn{3}{|c|}{ HST nước ngọt } & \multicolumn{3}{|c|}{ HST nước lợ } \\
\hline & & $\begin{array}{c}\text { Trong } \\
(\mathrm{n}=60)\end{array}$ & $\begin{array}{c}\text { ngoài } \\
(\mathrm{n}=60)\end{array}$ & $\begin{array}{l}\text { Vùng ngọt } \\
(\mathrm{n}=120)\end{array}$ & $\begin{array}{c}\text { Trong } \\
(\mathrm{n}=60)\end{array}$ & $\begin{array}{c}\text { ngoài } \\
(\mathrm{n}=60)\end{array}$ & $\begin{array}{l}\text { Vùng lợ } \\
(\mathrm{n}=120)\end{array}$ \\
\hline 1 & Lú dây & $\overline{5,0}$ & 6,7 & $\overline{5,8}$ & 25,0 & 5,0 & 15,0 \\
\hline 2 & Chất chà & 5,0 & 1,7 & 3,3 & & & \\
\hline 3 & Lưới giăng & 50,0 & 60,0 & 55,0 & & 3,3 & 1,7 \\
\hline 4 & Lưới cào & & 6,7 & 3,3 & 1,7 & 1,7 & 1,7 \\
\hline 5 & Lú miệng & 6,7 & 16,7 & 11,7 & 53,3 & 41,7 & 47,5 \\
\hline 6 & Đáy & & & & 15,0 & 56,7 & 35,8 \\
\hline 7 & Nò & & & & 5,0 & & 2,5 \\
\hline 8 & Chài rê & & & & 1,7 & & 0,8 \\
\hline 9 & Đó & & & & 6,7 & & 3,3 \\
\hline 10 & Giăng câu & & & & 1,7 & & 0,8 \\
\hline 11 & Rọ & & & & 1,7 & 1,7 & 1,7 \\
\hline 12 & Chúm & 5,0 & & 2,5 & & & \\
\hline 13 & Dớn & 26,7 & 30,0 & 28,3 & & & \\
\hline 14 & Vó & 8,3 & 3,3 & 5,8 & & & \\
\hline 15 & Cào lịch/lươn & 1,7 & & 0,8 & & & \\
\hline 16 & Câu cắm & 6,7 & & 3,3 & & & \\
\hline 17 & Chài quăng & 3,3 & 1,7 & 2,5 & & & \\
\hline 18 & Kéo côn & 5,0 & & 2,5 & & & \\
\hline 19 & Lờ/lợp & 3,3 & & 1,7 & & & \\
\hline 20 & Đăng mé & 3,3 & & 1,7 & & & \\
\hline 21 & Lưới kéo tay & 1,7 & 6,7 & 4,2 & & & \\
\hline 22 & Xiệc điện & 1,7 & 1,7 & 1,7 & & & \\
\hline 23 & Bắt tay (ốc) & 1,7 & & 0,8 & & & \\
\hline 24 & Xà di & & 1,7 & 0,8 & & & \\
\hline
\end{tabular}

Bảng 8. Sản lượng cá, tôm khai thác trong năm 2016 theo ngư cụ

\begin{tabular}{lcc}
\hline Ngư cự & HST nước ngọt & HST nước lợ \\
\hline Sản lượng khai thác ở sông rạch (kg/năm) & & \\
Lú dây & $526,8 \pm 353,7$ & $175,0 \pm 90,2$ \\
Lưới giăng & $333,0 \pm 475,2$ & $273,2 \pm 244,9$ \\
Lú miệng & $293,3 \pm 174,4$ & $178,5 \pm 171,2$ \\
Dớn & $550,5 \pm 887,1$ & - \\
Đáy & - & $201,0 \pm 124,4$ \\
Sản lượng khai thác ở đồng ruộng (kg/năm) & \\
Lú dây & $270,7 \pm 169,0$ & - \\
Lưới giăng & $355,0 \pm 406,9$ & - \\
Lú miệng & $456,5 \pm 313,0$ & - \\
Dớn & $312,3 \pm 253,4$ & - \\
\hline
\end{tabular}

2012 và sản lượng bên trong HTCTTL thấp hơn bên ngoài HTCTTL. Kích cỡ các loài thủy sản khai thác tự nhiên ở vùng nghiên cứu tương đối nhỏ. Một số loài cá bản địa rất ít khi xuất hiện ở HST nước ngọt như Channa lucius, No- topterus notopterus, Clarias macrocephalus, Clarias batrachus, Morulius chrysophekadion và Toxotes chatareus, tương tự ở HST nước lợ có loài $A r$ ius maculatus và Otolithoides biauritus. Loài cá lau kiếng Pterygoplichthys disjunctivus đã thiết 
Bảng 9. Biến động sản lượng thủy sản khai thác ở hệ sinh thái nước ngọt

\begin{tabular}{lccc}
\hline Địa điểm & Năm & Sản lượng $(\mathrm{kg} / \mathrm{h} \hat{\text { ọ̆ }} \mathrm{năm})$ & Nguồn thông tin \\
\hline \multirow{3}{*}{ HST nước ngọt } & 2000 & $1.282,2$ & Le \& ctv. (2007) \\
\cline { 2 - 4 } & 2006 & $1.016,7$ & \\
\cline { 2 - 4 } Trong & 2012 & 793,4 & Le \& ctv. (2007) \\
& 2016 & 521,1 & \\
\hline \multirow{3}{*}{ Ngoài } & 2000 & $1.091,1$ & Le \& ctv. (2007) \\
& 2012 & 653,7 & \\
& 2016 & 2740,2 & \\
\hline
\end{tabular}

Bảng 10. Kích cỡ bình quân một số loài cá khai thác thường xuyên tại vùng nghiên cứu

\begin{tabular}{clcccccc}
\hline \multirow{2}{*}{ TT } & \multirow{2}{*}{ Tên khoa học } & \multicolumn{3}{c}{ Chiều dài tổng $(\mathrm{cm})$} & \multicolumn{3}{c}{ Khối lượng $(\mathrm{g})$} \\
\cline { 3 - 8 } & & $\begin{array}{c}\text { Trung } \\
\text { bình }\end{array}$ & $\begin{array}{c}\text { Nhỏ } \\
\text { nhất }\end{array}$ & $\begin{array}{c}\text { Lớn } \\
\text { nhất }\end{array}$ & $\begin{array}{c}\text { Trung } \\
\text { bình }\end{array}$ & $\begin{array}{c}\text { Nhỏ } \\
\text { nhất }\end{array}$ & $\begin{array}{c}\text { Lớn } \\
\text { nhất }\end{array}$ \\
\hline 1 & Anabas testudineus & $9,2 \pm 2,5$ & 4,3 & 19 & $18,3 \pm 15,7$ & 0,79 & 97,99 \\
2 & Barbonymus gonionotus & $15,5 \pm 3,4$ & 7,1 & 27,8 & $63,2 \pm 49$ & 4,4 & 335,64 \\
3 & Boesemaria microlepis & $8,8 \pm 4,0$ & 2,7 & 32,5 & $8,1 \pm 18,6$ & 0,12 & 265,04 \\
4 & Butis butis & $7,5 \pm 1,7$ & 4 & 9,8 & $4,5 \pm 2,5$ & 0,49 & 8,85 \\
5 & Channa striata & $22.1 \pm 3,8$ & 11,9 & 29,5 & $103,8 \pm 55,9$ & 16,7 & 235,62 \\
6 & Cirrhinus molitorella & $10,5 \pm 3,2$ & 6,5 & 18,5 & $14,8 \pm 15,6$ & 1,81 & 62,96 \\
7 & Cynoglossus lingua & $10,5 \pm 2,6$ & 3,8 & 28,3 & $4,3 \pm 4,1$ & 0,13 & 73,68 \\
8 & Eleotris melanosoma & $6,8 \pm 1,5$ & 2,7 & 12,2 & $4,6 \pm 3,3$ & 0,14 & 27,03 \\
9 & Glossogobius giuris & $10,0 \pm 3,2$ & 1,8 & 20,2 & $9,5 \pm 13,8$ & 0,49 & 12,39 \\
10 & Labiobarbus siamensis & $9,4 \pm 1,2$ & 6 & 15,2 & $8,1 \pm 4,4$ & 2,25 & 35,96 \\
11 & Parambassis wolffii & $9,0 \pm 2,7$ & 3,8 & 16,3 & $13,0 \pm 10,7$ & 0,44 & 58,86 \\
12 & Polynemus aquilonaris & $9,5 \pm 2,3$ & 4,6 & 19,5 & $6,3 \pm 6,3$ & 0,53 & 51,54 \\
13 & Pterygoplichthys disjunctivus & $20,3 \pm 5,9$ & 2 & 37,6 & $79,9 \pm 67,7$ & 3,32 & 398,57 \\
14 & Puntioplites proctozystron & $10,0 \pm 2,6$ & 5,3 & 21,8 & $17,2 \pm 18,2$ & 1,66 & 198,84 \\
15 & Trichopodus trichoterus & $7,99 \pm 1,0$ & 4 & 11,5 & $7,6 \pm 3,66$ & 0,6 & 22,62 \\
16 & Trichopodus microlepis & $9,4 \pm 1,61$ & 5 & 14,1 & $10,3 \pm 5,9$ & 1,19 & 39.46 \\
17 & Mystus atrifasciatus & $9,7 \pm 1,3$ & 6,7 & 14,6 & $7,9 \pm 3,4$ & 3,1 & 24,6 \\
18 & Oreochromis mossambiucus & $10,9 \pm 3,8$ & 5,7 & 23,5 & $32,5 \pm 48,6$ & 2,01 & 270,34 \\
\hline
\end{tabular}

lập quần đàn trên nhiều thủy vực gây cạnh tranh, đe dọa tính đa dạng và sự phong phú của các loài cá bản địa. Có nhiều nguyên nhân gây nên sự suy giảm đáng kể NLTS ở vùng nghiên cứu trong đó nổi bật nhất là do HTCTTL ngăn chặn đường di cư của các loài thủy sản, nhiều ngư dân sử dụng các loại ngư cụ khai thác có tính hủy diệt như: sử dụng xiệc điện, thuốc độc, bắt cá bố mẹ và cá con trong mùa sinh sản và do ảnh hưởng của các chất thải từ hoạt động cải tạo ao/đầm nuôi trồng thủy sản ở vùng nghiên cứu.

\section{2. Đề xuất}

Để giảm thiểu những bất lợi do HTCTTL gây ra cho cộng đồng và NLTS tại vùng nghiên cứu, việc thiết kế và vận hành hệ thống này cần có sự tham gia và đồng thuận của người dân ở mỗi tiểu vùng, nên chú ý tới khả năng cung cấp phù sa và rửa phèn cho đất đai cũng như khả năng di cư và sinh sản của nhiều loài thủy sản, nhất là những loài di cư theo mùa lũ, kể cả giao thông thủy nội vùng và ngoài vùng dự án. 


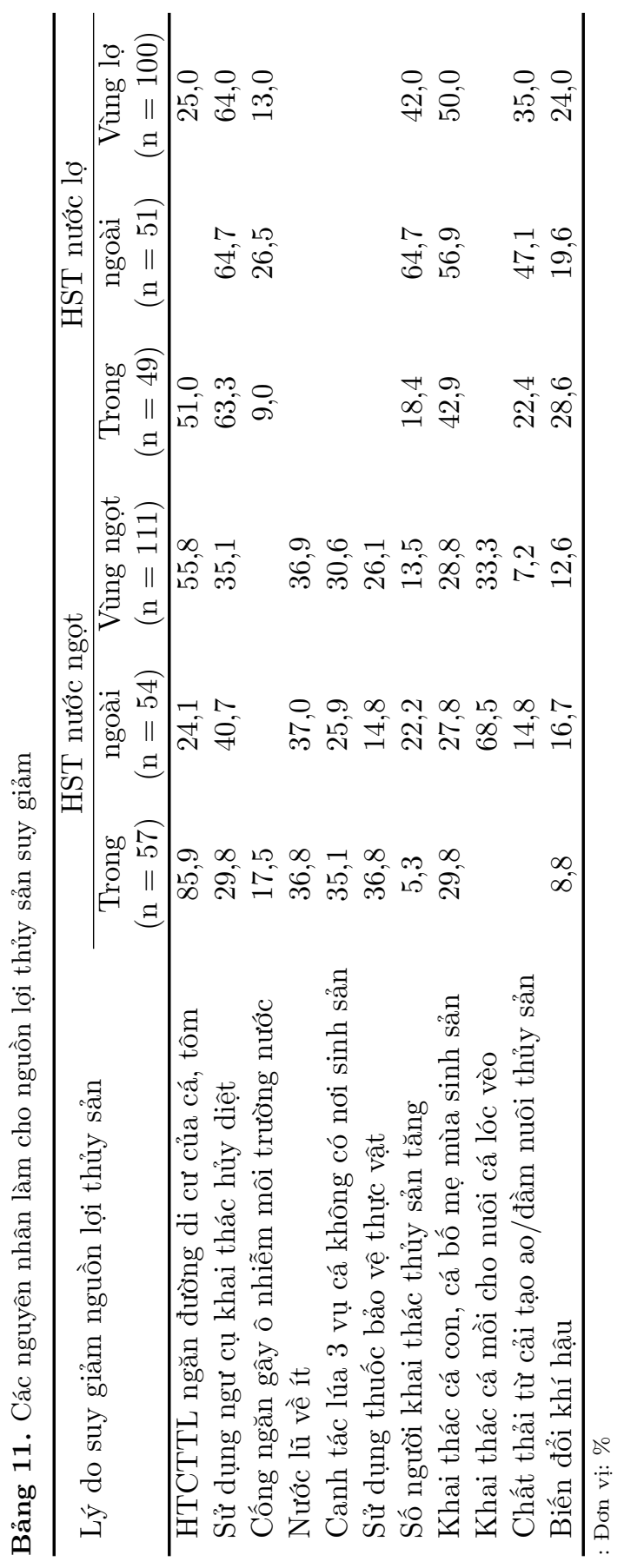

Cần tránh các hoạt động khai thác cá vào mùa sinh sản nhằm tạo điều kiện giúp cá tái tạo quần đàn tự nhiên. Khuyến khích các nghề khai thác có tính chọn lọc (lưới rê, câu, chài rê, chài quăng có kích thước mắt lưới phù hợp với cỡ cá khai thác), giới hạn ngư trường, quy định thời gian, mùa vụ khai thác với các ngư cụ không chọn lọc (đăng mé, đáy, lưới cào, lưới kéo nội đồng, kéo côn), những nghề khai thác bị động (chà, vó, nò, lờ, lợp, dớn). Tăng cường có hiệu quả biện pháp kiểm tra, phát hiện và xử lý vi phạm việc khai thác bằng các ngư cụ có tính hủy diệt (dùng chất độc, xiệc điện).

Chú trọng nghiên cứu khoa học ứng dụng phòng trừ sinh học và giải pháp tổng hợp trong kiểm soát, diệt trừ loài cá lau kiếng xâm hại ở các loại hình thủy vực. Nâng cao ý thức bảo vệ các loài thủy sản bản địa, loài nguy cấp, có nguy cơ tuyệt chủng, đa dạng các mô hình NTTS để giảm áp lực khai thác thủy sản tự nhiên ở vùng nghiên cứu.

\section{Tài Liệu Tham Khảo (References)}

Dang, K. S. (2010). Irrigation and aquaculture development in the Mekong river delta. Retrieved October 22, 2015, from http://www.tongcucthuyloi.gov.vn/Thuyloi-va-phat-trien-nuoi-trong-thuy-san-vung-dongbang-song-Cuu-Long.

Dang, T. N., \& Ho, H. T. (2001). Fauna of Vietnam 5. Ha Noi, Vietnam: Science and Technics Publishing House.

Eschmeyer, W. N. (1998). Catalog of fishes (Vol. 1, 2, 3). San Francisco, USA: California Academy of Sciences.

Froese, R., \& Pauly, D. (2018). FishBase. Retrieved February 02, 2018, from http://www.fishbase.org.

Haskoning, B. V., Euroconsult, \& Delft, D. (1997). Mid-term report. (Irrigation development project in Mekong Delta).

Le, S. X., Do, C. M., Huynh, H. V., Dang, P. T., \& Vo, T. T. (2007). Impact of flood control system on aquatic resources and communities in the average flooded area of the Mekong river delta. Scientific conference on sustainable development of the Mekong river delta after Vietnam joins WTO (WTO) (243-250). Can Tho, Vietnam: Can Tho University.

Mai, V. V., Tran, D. D., Ngo, T. T. D., Huynh, H. V., Dang, P. T., Nguyen, T. T., \& Nguyen, Q. T. K. (2016). The role of aquatic resources and the impact of irrigation project sub-regions on the livelihood of the fishing community in the Ca Mau peninsula (Summary report). Can Tho, Vietnam: Can Tho University.

Mai, Y. D., Nguyen, T. V., Nguyen, T. V., Le, Y. H., \& Hua, L. B. (1992). Classification of freshwater fish species in southern Vietnam. Ha Noi, Vietnam: Science and Technics Publishing House. 
Palomares, M. L. D., \& Pauly, D. (Eds.). (2018). SeaLifeBase. Retrieved February 2, 2018, from http://www.sealifebase.org.

Tang, T. D. (2011). The issues on controlling water resources in Ca Mau peninsula. Agriculture and Rural Development 2, 35-41.
Tran, D. D., Shibukawa, K., Nguyen, P. T., Ha, H. P., Tran, L. X., Mai, H. V., \& Utsugi, K. (2013). Fishes of the Mekong Delta, Vietnam. Can Tho, Vietnam: Can Tho University. 